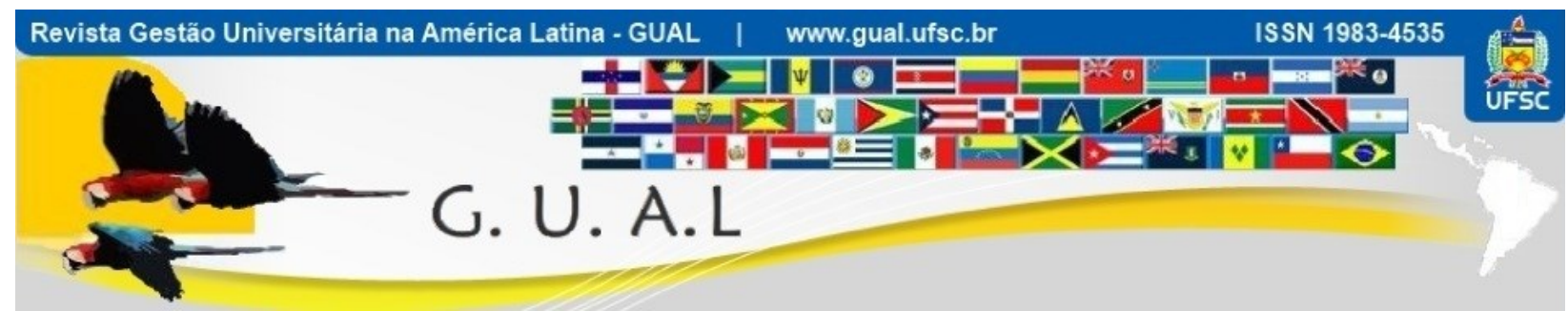

DOI: http://dx.doi.org/10.5007/1983-4535.2019v12n1p97

\title{
EFETIVIDADE DAS DECLARAÇÕES DE MISSÃO INSTITUCIONAL: ANÁLISE DAS DECLARAÇÕES DAS INSTITUIÇÕES FEDERAIS DE ENSINO SUPERIOR (IFES)
}

\section{EFFECTIVENESS OF INSTITUTIONAL MISSION STATEMENTS: ANALYSIS OF STATEMENTS OF FEDERAL INSTITUTIONS OF HIGHER EDUCATION}

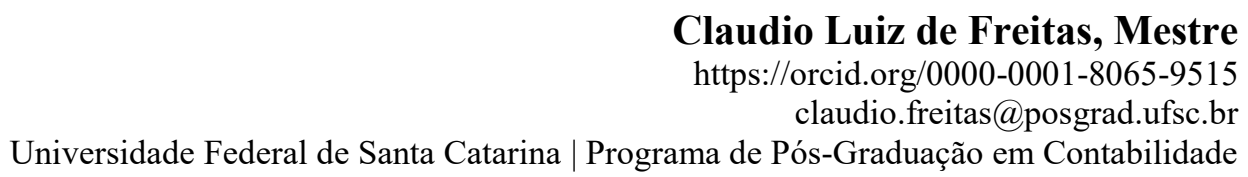

Florianópolis | Santa Catarina | Brasil

Elisa Elena Espindola, Bacharel

https://orcid.org/0000-0002-3448-9612

elisa_espindola@yahoo.com.br

Universidade Federal de Santa Catarina | Departamento de Ciências Contábeis Florianópolis | Santa Catarina | Brasil

Rogério João Lunkes, Doutor https://orcid.org/0000-0003-4232-5746 rogeriolunkes@bol.com.br

Universidade Federal de Santa Catarina | Programa de Pós-Graduação em Contabilidade | Departamento de Ciências Contábeis Florianópolis | Santa Catarina | Brasil

Elisete Dahmer Pfitscher, Doutora https://orcid.org/0000-0001-8711-9642 elisete.pfitscher@ufsc.br

Universidade Federal de Santa Catarina | Programa de Pós-Graduação em Contabilidade | Departamento de Ciências Contábeis Florianópolis | Santa Catarina | Brasil

Recebido em 26/fevereiro/2017

Aprovado em 03/agosto/2018

Publicado em 02/janeiro/2019

Sistema de Avaliação: Double Blind Review

Esta obra está sob uma Licença Creative Commons Atribuição-Uso. 


\title{
RESUMO
}

A missão institucional de uma organização, se bem elaborada constitui-se como uma importante ferramenta de apoio à gestão estratégica das instituições. Nesse sentido, o presente trabalho tem como objetivo analisar o status quo da missão institucional das Instituições Federais de Ensino Superior (IFES) brasileiras, a partir dos elementos propostos por Pearce (1982) e Pearce e David (1987). Para tanto a trajetória metodológica adotada divide-se em três partes: Revisão de literatura; Coleta de dados e; análise dos resultados. O estudo assume caráter descritivo com abordagem qualitativa do problema e utilização de fonte secundária de pesquisa. Os resultados evidenciam que, adotados os estudos de Pearce (1982) e Pearce e David (1987), nenhuma das IFES brasileiras possui efetividade integral da missão institucional. Os elementos que foram identificados com maior frequência foram "Referencia ao produto ou serviço" e "Compromisso com o desenvolvimento sustentável (econômico/social/ambiental)", ao passo que os elementos que se referem a "filosofia e valores da organização" e "imagem da organização" são pouco lembrados nas declarações de missão. Da análise comparativa do status quo da missão das IFES, por região do país, concluíse que as regiões sul e sudeste concentram as universidades que possuem as missões institucionais mais efetivas e que elementos como referência a corpo funcional e outros stakeholders não são contemplados em nenhuma das instituições.

Palavras-chave: Missão Institucional. Efetividade. Instituições Federais de Ensino Superior. IFES.

\begin{abstract}
The institutional mission of an organization, if well elaborated, constitutes an important tool to support strategic management. Thus, this study aims to analyze the status quo of the institutional mission of Federal Institutions of Higher Education in Brazil, from the elements proposed by Pearce (1982) and Pearce and David (1987). For this, the methodology adopted is divided into three parts: literature review, data collection and analysis results. The study has a descriptive feature with a qualitative approach to the problem and use of secondary source research. The results reveal that, according to studies of Pearce (1982) and Pearce and David (1987), none of the Brazilian Federal Institutions of Higher Education has comprehensive effectiveness of the institutional mission. The elements that were identified most frequently were "reference to the product or service" and "commitment to sustainable development (economic / social / environmental)", while the elements that refer to "organization philosophy and values" and "organization image" were little remembered in the mission statements. The conclusion from the comparative analysis of the status quo of Federal Institutions of Higher Education mission, by region of the country, is that the south and southeast universities focus institutional missions that are more effective and that elements such as reference to workforce and other stakeholders are not addressed in none of the institutions.
\end{abstract}

Keywords: Institutional Mission. Effectiveness. Federal Institutions of Higher Education. 


\section{INTRODUÇÃO}

Para analisar a gestão estratégica de uma organização, conhecer a missão institucional dessa organização se torna necessário, uma vez que a missão institucional, enquanto componente do planejamento estratégico, pode revelar muito sobre a organização e sua forma de gestão, se construída de forma a permitir sua efetividade.

As declarações de missão evidenciam um conjunto de objetivos, interesses e cultura de uma organização, para os stakeholders, a fim de que a gestão estratégica da empresa possa se nortear para a condução das ações e atingimento de metas previamente definidas no planejamento estratégico.

Para Drucker (1975) a declaração de missão deve ser realista, de forma a permitir o estabelecimento de estratégias e políticas para que se possam iniciar as atividades. Já Leithesser e Kohli (1997) revelam que a declaração de missão direcionada, interna e externamente, possibilita a transmissão de diretrizes aos usuários, envolvidos nos processos da organização.

Vários estudos abordam essa temática, seja evidenciando aspectos e elementos que compõem a missão institucional e revelam o seu status quo, seja analisando a inclusão de tais elementos e aspectos nas declarações de missão das organizações, dois quais se pode destacar, dentre outros; Pearce, 1982; Rarick; Vitton, 1995; Greengarten-Jackson et al, 1996; Campbell, 1997; Bart; Baetz, 1998; Bartkus; Glassman; McAfee, 2000; Bart; Bontis; Taggar, 2001; Smith et al, 2001; Amato; Amato, 2002; Bart e Bontis, 2003; Bart; Hupfer, 2004; Bartkus; Glassman, 2008; Ribeiro et al, 2008; Fugazzotto, 2009.

Ao se tratar de instituições de ensino, o assunto assume originalidade, uma vez que nessas instituições, o status quo e a consistência de uma missão institucional é elemento de fundamental importância na gestão estratégica e no desempenho de suas atividades, quando bem disseminada entre os stakeholders.

Nesse sentido, a problemática da presente pesquisa centra-se na seguinte interrogação: Qual a efetividade da missão institucional das Instituições Federais de Ensino Superior (IFES) brasileiras?

Assim, partindo-se da estrutura de declaração de missão, proposta por Pearce (1982) e Pearce e David (1987) e com base na problemática de pesquisa, o objetivo geral desta pesquisa consiste em analisar o status quo da missão institucional das Instituições Federais de Ensino Superior (IFES) brasileiras, constantes da página eletrônica da Associação Nacional 
dos Dirigentes de Instituições Federais de Ensino Superior (ANDIFES).

Para tanto, os seguintes objetivos específicos serão perseguidos: (i) identificar os elementos, propostos por Pearce (1982) e Pearce e David (1987), respeitadas as adaptações necessárias, nas IFES; (ii) analisar comparativamente o status quo da missão institucional das IFES, por regiões; e (iii) analisar a extensão da missão institucional nas IFES que apresentarem melhor grau de efetividade da declaração, de acordo com a proposta dos trabalhos que embasam o presente estudo.

Frente ao exposto, o presente trabalho, estrutura-se da seguinte maneira: Esta seção inicial, de caráter introdutório; a seção 2 - Revisão Teórica - que discute a literatura acerca da temática pesquisada; a seção 3 - Metodologia - que apresenta a trajetória utilizada para condução e conclusão da pesquisa; a seção 4 - que apresenta e discute os resultados obtidos; a seção 5 que apresenta as conclusões; e por fim as referências que sustentaram a presente pesquisa.

\section{REVISÃO TEÓRICA}

\subsection{ENSINO SUPERIOR E INSTITUIÇÕES FEDERAIS DE ENSINO SUPERIOR (IFES)}

A respeito do surgimento das instituições de ensino superior no Brasil, a literatura não apresenta um consenso. Cunha (1999) afirma que já em 1550 os jesuítas já ofereciam cursos superiores na área de artes e teologia. Já outros autores entendem que o ensino superior no Brasil teve seu início ainda em 1808, com a chegada da família real e o embrião de escolas de medicina sendo instaladas no Rio de Janeiro e na Bahia. (HARDY; FACHIN, 1996; FINGER, 1997).

De acordo com Hardy e Fachin (1996) e Cunha (1999) a instituição de universidades, propriamente ditas, no Brasil foi um processo demorado, sendo constituídas inicialmente várias faculdades isoladas.

De acordo com Cunha (1999) a primeira universidade, que foi criada com essa denominação, foi a Universidade de Manaus, em 1909, e que alguns anos mais tarde, em 1926 encerrou suas atividades. Para o autor, no entanto, a primeira instituição a assumir duramente o status de universidade foi a Universidade Federal do Rio de Janeiro e a partir daí começa o desenvolvimento e expansão das universidades brasileiras, sejam no âmbito federal, estadual ou privado, que ainda assim, limita-se ao conceito de faculdade.

A partir de 1968, no entanto, com a reforma universitária visando à expansão dos 
cursos de graduação e criação de cursos de pós-graduação e pesquisas, consagra-se como um novo marco para o desenvolvimento do ensino superior no país e posteriormente com novas reformas e contrarreformas universitárias, ampliando o número de universidades e de vagas nas universidades.

Especificamente a respeito das universidades federais, os dados do Instituto Nacional de Estudos e Pesquisas Educacionais Anísio Teixeira (INEP) mostram que houve uma grande evolução na última década, em número de instituições e, consequentemente, em oferta de cursos e vagas para graduação e pós-graduação.

De acordo com o INEP (2000), de 1980 para 1990 foram criadas apenas duas novas universidades federais, passando de 34 para 36; e que de 1990 para 1998 foram criadas três novas universidades federais.

A Associação Nacional dos Dirigentes das Instituições Federais de Ensino Superior (ANDIFES) e o Ministério da Educação (MEC), no entanto, já apontam à significativa evolução ocorrida na última década, apontando, de acordo com dados do MEC que, atualmente, estão em funcionamento 58 universidades federais, contra 39 , no final da década de 1990.

Assim, diante do histórico do ensino superior brasileiro, e da expansão universitária, especialmente no âmbito das IFES, as ferramentas de gestão devem ser bem construídas de forma a permitir que os objetivos das instituições sejam concluídos com êxito. Nesse sentido o status quo e a efetividade da missão institucional tornam-se necessários e relevantes para a organização.

\subsection{A MISSÃO INSTITUCIONAL E SUA EFETIVIDADE}

A missão institucional de uma organização reflete a cultura da organização, expressando seus valores, crenças e objetivos que norteiam a sua forma de se posicionar perante a sociedade e demais stakeholders.

Para Pearce (1982, p.15), a declaração de missão institucional deve ter caráter abrangente e duradouro do propósito da organização, tendo a capacidade de distinguir a organização frente à concorrência.

Takeski e Rezende, (2000) entendem que a missão expressa o motivo da existência da organização, definindo sua finalidade junto à sociedade. Já Bart (2001) defende que a missão deve ter o potencial de captar uma lógica que justifique a existência e continuidade da 
organização. Ao passo que Valadares (2002) assume que a missão deve expressar a razão de existir da organização, contemplando seus objetivos e estratégias, de forma clara e compreensível.

Pearce (1982) afirma que a declaração de missão institucional de uma organização pode ser uma valiosa ferramenta para gestão estratégica, uma vez que fornece uma estrutura para desenvolver um sentido de missão da entidade que podem auxiliar no tratamento de várias demandas conflitantes que uma organização enfrenta em seus dois ambientes, interno e externas.

Para Teles e Lunkes (2011) a missão institucional consiste em um conjunto de crenças definidos com o objetivo de orientar as ações da organização, por meio do conhecimento de quem é a organização, por que existe e para onde vai, incluindo elementos que agreguem retorno à organização, sob a ótica dos seus diversos stakeholders.

Assim, a missão institucional é entendida como importante instrumento de gestão, uma vez que permite liderança e avaliação de desempenho, através do desenvolvimento de estratégias (Bartkus; Glassman, 2008; Nimwegen et al, 2008); e alinhamento entre as estratégias e cultura organizacional (Greengarten-Jackson et al, 1996; Fugazzotto, 2009).

Nesse sentido, a posição de Drucker (1975) de que a missão possui importância estratégica, sendo o marco inicial para estratégias, prioridades, planos e tarefas da organização, é ratificada pelos autores citados anteriormente.

Assim, a declaração de missão, em instituições de ensino superior deve refletir, com clareza, seus objetivos e estratégias, a fim de que a sua gestão seja exercida de forma eficaz e transparente.

Os impactos e reflexos que a missão institucional provoca na organização relacionamse com os benefícios que ela possui, assim é importante avaliar até que ponto a declaração de missão é, de fato, efetiva, enquanto ferramenta de apoio à gestão estratégica de uma organização.

Desta forma, de acordo com Pearce (1982), a missão institucional se caracteriza como ferramenta de apoio a gestão estratégica, quando apresenta, objetivamente, elementos que possam ser mensuráveis e avaliados periodicamente.

Neste sentido, Pearce (1982) apresenta os seguintes elementos, necessários, sob a ótica do autor, para que uma missão institucional possa ser considerada efetiva: (a) Produto ou serviço oferecido; (b) Publico alvo; (c) A tecnologia empregada na produção do produto ou 
serviço; (d) Sobrevivência, crescimento e lucratividade; (e) A filosofia organizacional; (f) A imagem pública; e $(\mathrm{g}) \mathrm{O}$ conceito próprio da organização; imagem transmitida para aqueles afiliados a ela.

Outras formas de se avaliar o status quo da missão institucional são conhecidas na literatura, como a avaliação de propósito, estratégia, valores, padrões de comportamento e clareza de escrita, propostos por Campbell (1991); os nove elementos-chave, propostos por David e David (2003); ou a relação com o desempenho organizacional, como evidenciaram Bart e Baetz (1998).

No entanto, por ser utilizada em grande parte dos trabalhos similares, nota-se a aceitação da proposta de Pearce, o que justifica a utilização de tal proposta, também, neste estudo, destacando-se a inclusão do elemento 'Domínio geográfico da organização', que foi contemplado no estudo de Pearce e David (1987).

Bart (1997) destaca, todavia, que a missão também pode apresentar falhas, que interferem no seu status quo. Tais falhas decorrem de equívocos na construção da declaração de missão e não da ferramenta em si e podem ser resumidos em falta de clareza e capacidade de atingir os propósitos a que ela se destina.

Assim, não é suficiente possuir uma declaração de missão, para que a gestão estratégica possa usufruir dos benefícios desta, mas é necessário que a missão institucional seja construída de forma consistente e clara.

\subsection{PESQUISAS SIMILARES SOBRE MISSÃO INSTITUCIONAL}

Várias pesquisas já estudaram as declarações de missão institucional, no entanto, nenhum dos trabalhos pesquisou sobre a efetividade das declarações de missão institucional nas Instituições Federais de Ensino Superior (IFES). Assim, apresentam-se nesta subseção algumas das principais pesquisas já realizadas acerca do tema missão institucional, elencandoas em ordem cronológica, a fim de que se possa observar o estado da arte e a evolução das pesquisas sobre a temática. Para tanto, ressalta-se que a delimitação temporal engloba as pesquisas, a partir de 2000 até o estágio atual.

Já em 2000, Bartkus, Glassman e McAfee (2000) fazem uma análise dos erros das declarações de missão comparados aos seus benefícios e descrevem o que realmente é uma declaração de missão, na percepção dos autores.

Bart, Bontis e Taggar (2001) fizeram a aplicação de um modelo próprio, desenvolvido 
anteriormente, em empresas europeias e canadenses. Descobriram que o compromisso com a missão institucional possui relação positiva com o comportamento dos funcionários e com o desempenho financeiro.

Já Bart (2001) investigou a eficiência da internet como meio de divulgação da missão institucional, pelas organizações. O autor verificou que, dentre as 100 maiores empresas da Fortune 500, 45 empresas divulgavam sua missão na internet, sendo a maioria instituições sem fins lucrativos.

Amato e Amato (2002) pesquisaram a relação entre a missão e a qualidade de vida dos colaboradores das organizações e a rentabilidade da organização. Concluíram que existe correlação positiva entre o ROI e o bem-estar da força de trabalho. Já Omran, Atrill e Pointon (2002) constataram que a orientação da missão não afeta o desempenho, quer em termos de retornos ou retornos excedentes, em pesquisa realizada com acionistas e stakeholders.

Sufi e Lyon (2003) pesquisaram as relações entre a declaração de missão e o volume de vendas, margem de lucro e retorno sobre o capital. Observaram que há correlação com as vendas, mas não há forte correlação com a margem de lucro e retorno sobre o capital.

Bart e Hupfer (2004) pesquisaram sobre as declarações de missão dos hospitais canadenses. Os autores concluíram que os elementos mais evidenciados são grandes inspirações, desempenho financeiro e stakeholders.

Seguindo a linha de Bart (2001), Biloslavo (2004) analisou as declarações de missão que foram publicadas nos sites das 50 maiores empresas eslovenas. O autor observou divergências em relação a empresas americanas e outras organizações e acredita que embora a globalização e a regionalização possam exercer impactos sobre a missão institucional, a convergência de conteúdos é questionável.

Nimwegen et al (2008) pesquisaram a relação entre a importância dos stakeholders e a inclusão de grupos de interessados nas declarações de missão. Os autores fizeram a análise sob a ótica da relação teórica alternativa, existente entre os fatos. Para isso os autores fizeram observações em aproximadamente quinhentas empresas, classificando as relações em mais ou menos dependentes, concluindo que os grupos mais dependentes são os grupos abordados com maior frequência nas declarações de missão das organizações.

Bartkus e Glassmann (2008) estudaram a relação entre os stakeholders e a declaração de missão das organizações. Os autores concluíram que a inclusão de grupos de interesse 
específico em missões é resultado de interesses institucionais e as questões sociais, embora sejam citadas, estão mais relacionadas a decisões políticas, do que efetivamente sociais.

Dentre as pesquisas realizadas no Brasil, destacam-se as pesquisas de Ribeiro et al (2008) e Teles e Lunkes (2011).

Ribeiro et al (2008) avaliaram os elementos que compõem a missão institucional das organizações de capital aberto listadas na BM\&FBOVESPA, utilizando, também, a pesquisa de Pearce (1982) como base. Os resultados evidenciaram que as empresas, na maioria dos casos, apresentam menos da metade dos elementos proposto para o status quo da missão institucional.

Já Teles e Lunkes (2011) seguiram a lógica da pesquisa de Ribeiro et al (2008) e pesquisaram a efetividade da missão institucional das cem maiores companhias de capital aberto no Brasil. O resultado apontou que nenhuma das companhias atingiu os oito elementos necessários para ter uma missão institucional totalmente efetiva, sob a ótica de Pearce (1982), ma que a imagem da organização, como elemento de efetividade da declaração de missão, dói o mais citado, evidenciando a preocupação das organizações pesquisadas com a exteriorização de suas declarações de missão.

\section{METODOLOGIA}

\subsection{ENQUADRAMENTO METODOLÓGICO}

A presente pesquisa é consiste em um levantamento, que de acordo com Tripodi, Fellin e Meyer (1981) são as pesquisas do tipo survey que têm o objetivo de descrever características de uma população designada, que neste caso consiste na análise do status quo da missão institucional das IFES.

A pesquisa assume caráter descritivo, visto se observa e analisa as declarações de missão das IFES, a fim de que se possa avaliar sua efetividade e seu status quo enquanto ferramenta de apoio à gestão estratégica.

Assim, a pesquisa descritiva tem como propósito fazer afirmações que descrevam aspectos de uma população ou analisar características e atributos específicos. Na pesquisa descritiva "o pesquisador não concentra sua atenção no porque se observa certa distribuição, mas no que é tal distribuição". (RICHARDSON, 1989, p.91)

Diante do apresentado, para a coleta de dados utilizou-se de dados secundários, disponíveis nos relatórios e sites das IFES pesquisadas. Para Colauto e Beuren (2003); Lino 
(2008) as fontes secundárias são as informações encontradas em pesquisas ou publicações anteriores. Ou seja, são dados que já receberam algum tipo de tratamento, ainda que não tenham sido analisados de forma científica.

Quanto à abordagem do problema esta pesquisa utiliza a abordagem qualitativa, pois pretende analisar e aprofundar os conhecimentos a cerca do tema estudado, sem que isso justifique o emprego de instrumental estatístico, para as análises realizadas. (RICHARDSON, 1989)

\subsection{POPULAÇÃO E AMOSTRA}

A presente pesquisa teve como população as Instituições Federais de Ensino Superior (IFES) que constavam da relação disponibilizada na página eletrônica da Associação Nacional dos Dirigentes de Instituições Federais de Ensino Superior (ANDIFES).

A referida página foi acessada no período de 15 a 21 de novembro de 2010 e, portanto, compreende apenas as IFES listadas até essa data. Assim, a página apresentou a seguinte população:

Tabela 1 População de Universidades e Institutos Tecnológicos Federais por região do país

\begin{tabular}{lccc}
\hline \multicolumn{1}{c}{ Região } & Universidades & Institutos Tecnológicos & Total \\
\hline Norte & 8 & - & 8 \\
Nordeste & 14 & 2 & 16 \\
Centro-Oeste & 5 & - & 5 \\
Sudeste & 19 & 2 & 21 \\
Sul & 9 & - & 9 \\
\hline Total & $\mathbf{5 5}$ & $\mathbf{4}$ & $\mathbf{5 9}$ \\
\hline
\end{tabular}

Fonte: Adaptado de ANDIFES (2010).

Para efeitos de padronização e análise dos resultados, a população considerada para a pesquisa excluiu os Institutos Tecnológicos, reduzindo a população a 55 universidades federais.

Dessas 55 IFES, apenas 19 não possuíam a declaração de missão divulgada no site ou no Programa de Desenvolvimento Interno (PDI); ou também não divulgavam o PDI, que foi utilizado como fonte de coleta de dados, além do próprio site da IFES.

Para essas 19 instituições foram enviadas e-mail, solicitando que disponibilizassem a missão institucional. De tal solicitação houve um retorno de cinco instituições, que também integraram a amostra da pesquisa, totalizando 41 universidades federais analisadas. 


\subsection{PROCEDIMENTOS DE COLETA E ANÁLISE DOS DADOS}

Para a coleta dos dados, utilizou-se de fonte secundária, que consiste em contribuições ou informações já publicadas sobre o assunto. (COLAUTO; BEUREN, 2003; LINO, 2008).

Assim, depois de selecionada a amostra da presente pesquisa, acessou-se os sites das IFES e buscou-se a missão institucional. Nas instituições que possuíam link para uma página institucional, a missão foi pesquisada nesse link. Para as instituições que não possuíam uma página institucional, ou não disponibilizaram a declaração de missão nessas páginas, buscouse pelo PDI, que na maioria das IFES continha a declaração de missão.

Para as instituições em que não foi possível localizar a missão institucional, foram enviados e-mails solicitando o envio do texto da declaração de missão.

Ressalta-se que as análises realizadas limitaram-se a declaração de missão, não incluindo visão, valores e princípios, quando apresentados de forma separada; e excluindo-se esses elementos da análise, quando apresentados juntamente com o conceito de missão na declaração de missão da instituição.

Adotados os procedimentos de coleta de dados, procedeu-se a análise dos dados. Para tanto, realizou-se a leitura integral das missões e classificou-as, com suporte da planilha eletrônica Microsoft Excel 2007, de acordo com os elementos proposto por Pearce (1982) e Pearce e David (1987).

Assim, baseando-se nos elementos propostos por Pearce (1982) e Pearce e David (1987), analisou-se o conteúdo de cada declaração de missão e a correspondência com os elementos propostos pelo referido autor. A partir dessa análise construíram-se as análises e discussões dos resultados.

\section{APRESENTAÇÃO DOS RESULTADOS}

Para a análise dos resultados, adotou-se o modelo proposto por Pearce (1982) que contempla oito elementos que uma missão deve possuir para se tornar efetiva. Por se tratar de organizações federais que, portanto, não possuem fins lucrativos, o elemento que trata da sobrevivência e lucratividade não foi considerado nesse trabalho, para efeitos de análise. Todavia, considerou-se o elemento "Domínio geográfico", incluído, mais tarde por Pearce e David (1997).

Nesse sentido, as análises foram estratificadas por regiões do país e na seqüência apresenta-se uma análise comparativa dos resultados. 


\subsection{ANÁLISE DA MISSÃO DAS IFES, POR REGIÃO DO PAÍS}

Inicialmente apresenta-se a análise para a região Norte. Para esta região foram pesquisadas oito instituições. Adotando-se o procedimento indicado no item 3.3, não foi possível obter a declaração de missão da Universidade Federal Rural do Amazonas (UFRA) e da Universidade Federal de Rondônia (UNIR).

Assim, partindo-se da proposta de Pearce (1982), observou-se que as Instituições Federais de Ensino Superior (IFES) da região norte apresentam de 3 a 5 elementos.

Com base no trabalho de Pearce (1982) tem-se que tais instituições não possuem uma missão institucional totalmente efetiva, uma vez que não contemplam os oito elementos necessários para que uma missão seja considerada integralmente efetiva.

Os elementos mais adotados por estas instituições referem-se a "Referência a produto ou serviço" e "Compromisso com o desenvolvimento sustentável (econômico, social e ambiental)". Tais elementos foram encontrados em todas as IFES pesquisadas, da região norte, conforme evidência a Tabela 2.

Tabela 2 Elementos identificados nas missões institucionais das IFES da região Norte

\begin{tabular}{lc}
\hline \multicolumn{1}{c}{ ELEMENTOS IDENTIFICADOS } & FREQUÊECIA \\
\hline Referência aos produtos ou serviços & 6 \\
Compromisso com o desenvolvimento sustentável (econômico/ social/ ambiental) & 6 \\
Domínio Geográfico & 5 \\
Publico Alvo & 3 \\
Tecnologia utilizada & 3 \\
Imagem da organização & 1 \\
Filosofia e valores da organização & 1 \\
Preocupação com qualidade & 0 \\
\hline
\end{tabular}

Fonte: Elaborada pelos autores.

Apesar de não se mostrarem efetivas as declarações de missão das IFES da região norte apresentam o mínimo de elementos e informações necessárias, embora um importante elemento não tenha sido identificado em nenhuma delas, que se refere à qualidade do serviço prestado.

Já em relação às IFES da região nordeste, observa-se que algumas destas instituições já possuem maior efetividade em sua missão, apresentando até seis dos elementos propostos por Pearce (1982).

Na região nordeste foram pesquisadas quatorze instituições, das quais não foi possível obter a declaração de missão institucional da Universidade Federal da Bahia (UFBA); da 
Universidade Federal de Campina Grande (UFCG); e da Universidade Federal do Maranhão (UFMA).

Novamente os elementos mais citados nas missões foram: "Referência a produto ou serviço" e "Compromisso com o desenvolvimento sustentável (econômico, social e ambiental)" que, no entanto, não foram identificados em todas as instituições, como ocorreu nas IFES da região norte.

Tabela 3 Elementos identificados nas missões institucionais das IFES da região Nordeste

\section{ELEMENTOS IDENTIFICADOS}

FREQUÊNCIA

Referência aos produtos ou serviços

Compromisso com o desenvolvimento sustentável (econômico/ social/ ambiental)

Domínio Geográfico

Publico Alvo

Preocupação com qualidade

Tecnologia utilizada

Filosofia e valores da organização

Fonte: Elaborada pelos autores.

Observa-se, então, a maior preocupação das IFES da região nordeste em apresentar o elemento "Preocupação com qualidade" e "imagem da organização", mas por outro lado não foi identificado o elemento "Filosofia e valores da organização".

Em relação à região Centro-Oeste foi pesquisado cinco instituições, no entanto, só foi possível obter a declaração de missão da Universidade Federal de Goiás (UFG) e da Universidade Federal do Mato Grosso (UFMT), das quais se destaca esta última em que se identificaram seis dos oito elementos propostos por Pearce (1982), contra três da UFG. Ambas as instituições apresentaram em suas declarações de missão referencia ao serviço prestado, preocupação com o desenvolvimento sustentável e alguma referência de público-alvo. Não apresentaram, no entanto, elementos que se referem à imagem da instituição e filosofia e valores.

Na região Sudeste foi pesquisado dezenove instituições, não sendo possível obter a declaração de missão da Universidade Federal de Juiz de Fora (UFJF); Universidade Federal de Ouro Preto (UFOP); Universidade Federal de São João Del-Rei (UFSJ); Universidade Federal Rural do Rio de Janeiro (UFRRJ); Universidade Federal de São Carlos (UFSCar); e Universidade Federal de São Paulo (Unifesp).

$\mathrm{Na}$ região sudeste identificou-se uma das instituições que possuem missão 
institucional com maior efetividade, de acordo com Pearce (1982), sendo identificados até 7 elementos, em uma das IFES pesquisadas.

Tabela 4 Elementos identificados nas missões institucionais das IFES da região Sudeste

\begin{tabular}{lc}
\hline \multicolumn{1}{c}{ ELEMENTOS IDENTIFICADOS } & FREQUENNCIA \\
\hline Referência aos produtos ou serviços & 13 \\
Compromisso com o desenvolvimento sustentável (econômico/ social/ ambiental) & 12 \\
Publico Alvo & 11 \\
Preocupação com qualidade & 9 \\
Tecnologia utilizada & 7 \\
Domínio Geográfico & 5 \\
Filosofia e valores da organização & 3 \\
Imagem da organização & 2 \\
\hline
\end{tabular}

Fonte: Elaborada pelos autores.

A Tabela 4 evidencia que, ao contrário do que ocorreu nas outras regiões, na região sudeste todos os itens foram identificados, no conjunto de instituições, no entanto, nenhuma das instituições contemplou, isoladamente, todos os oito elementos analisados.

A maior incidência de elementos que tornam a missão efetiva, identificados nas IFES da região sudeste foi de 7 elementos. Observa-se a diferença em relação à freqüência dos elementos a partir do terceiro elemento mais identificado, uma vez que os dois mais identificados prevalecem nas outras regiões.

Por fim analisou-se a missão institucional das IFES da região sul. Observou-se que as IFES dessa região apresentam de 2 a 7 elementos e que o elemento mais citado, identificado em todas as instituições é o "Compromisso com o desenvolvimento sustentável (econômico/ social/ ambiental)", diferentemente do que ocorreu nas outras regiões, onde o elemento mais citado era a "Referência aos produtos ou serviços".

Os elementos que foram menos identificados na declaração de missão das IFES da região sul foram os referentes à tecnologia utilizada, imagem da organização e domínio geográfico, que apareceram apenas duas vezes.

A região sul foi à única em que se conseguiu acesso a declaração de missão de todas as nove instituições pesquisadas.

\subsection{ANÁLISE COMPARATIVA DA MISSÃO DAS IFES}

Em relação à missão das IFES, de forma geral, os elementos mais identificados foram "Referência aos produtos e serviços" e "Compromisso com o desenvolvimento sustentável (econômico/ social/ ambiental)" e os menos citados foram os elementos referentes à imagem e 
filosofia e valores da organização, conforme explícito na Tabela 5.

Tabela 5 Elementos identificados nas missões institucionais das IFES brasileiras

\begin{tabular}{lc}
\hline \multicolumn{1}{c}{ ELEMENTOS IDENTIFICADOS } & FREQUÊNCIA \\
\hline Referência aos produtos ou serviços & 37 \\
Compromisso com o desenvolvimento sustentável (econômico/ social/ ambiental) & 37 \\
Publico Alvo & 26 \\
Preocupação com qualidade & 18 \\
Domínio Geográfico & 18 \\
Tecnologia utilizada & 13 \\
Filosofia e valores da organização & 9 \\
Imagem da organização & 8 \\
\hline
\end{tabular}

Fonte: Elaborada pelos autores.

Observa-se da Tabela 5, em relação aos resultados já apresentados, que há um padrão na maioria das IFES, com a predominância dos dois primeiro elementos (Referência aos produtos ou serviços e Compromisso com o desenvolvimento sustentável (econômico/social/ambiental) e a pouca incidência dos dois últimos elementos (Filosofia e valores da organização e Imagem da organização).

Ressalta-se a pouca incidência do elemento Filosofia e valores da organização, dado que a pesquisa limitou-se as declarações de missão institucional, não contemplando na análise a visão, valores e princípios da organização que, acredita-se, contemplariam esses elementos em seu escopo.

Observa-se, ainda, que não foram identificados em nenhuma das instituições, elementos que se referissem ao corpo funcional, seja referindo-se aos técnico-administrativos, seja referindo-se aos docentes. A referência ao corpo discente, que se constitui como público alvo das instituições é realizada em várias das IFES, mas muitas vezes de forma implícita.

Em relação ao público alvo destaca-se, ainda, que este é composto, no caso das IFES, por toda a comunidade para a qual seus serviços são oferecidos e, neste caso, o conceito de comunidade é entendido, pelos autores desta pesquisa, como o conceito mais amplo e abrangente, envolvendo usuários internos e externos, diretos e indiretos, que de alguma forma se beneficiam dos serviços e do produto final (pesquisas e tecnologias, por exemplo) gerados pelas IFES.

Outro elemento, que embora não seja contemplado pela proposta de Pearce (1982) e Pearce e David (1987), mas que se considerou relevante é a questão de atendimento a legislação ou compliance,elemento para o qual não se observou a incidência, em nenhuma das 
instituições pesquisadas.

Em relação à efetividade, propriamente dita, nenhuma das IFES brasileiras atinge o nível máximo de efetividade de sua missão institucional, analisada pela ótica de Pearce (1982) e Pearce e David (1987), ou seja, apresentando todos os oito elementos propostos pelos referidos trabalhos, conforme evidencia o Gráfico 1.

Gráfico 1 Número de elementos identificados na missão institucional das IFES.

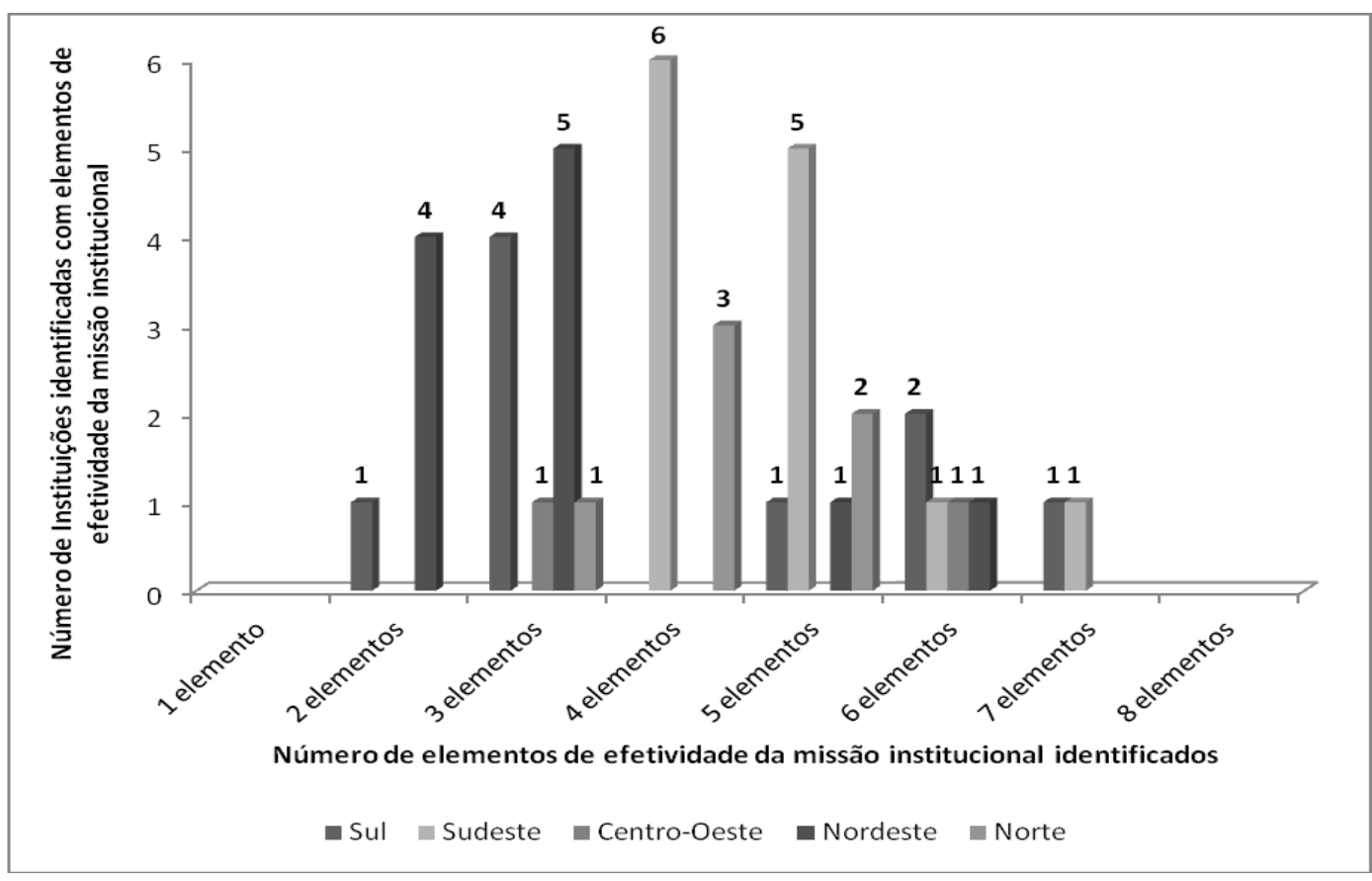

Fonte: Elaborado pelos autores.

Das quarenta e uma IFES pesquisadas, apenas dezesseis apresentaram 5 ou mais elementos, sendo que a média foi de aproximadamente 4 elementos e nenhuma das instituições chegou ao máximo de 8 elementos.

Apenas a Universidade Federal de Minas Gerais (UFMG) e a Universidade Federal do Pampa (Unipampa) atingiram o nível de sete elementos na missão institucional, que de acordo com os estudos que embasam esta pesquisa, as classifica como as IFES que possuem a missão institucional mais efetiva, dentre as pesquisadas.

Em ambas as instituições, UFMG e Unipampa, o elemento que não foi identificado foi o que se refere à tecnologia utilizada.

Observou-se, ainda, que as regiões sul e sudeste concentram as instituições que possuem as missões mais efetivas, estando à maioria das instituições dessas duas regiões, acima da média de elementos identificados nas missões de todas as instituições. 
Levantados o ranking de identificação dos elementos, e o número de elementos contemplados por cada instituição, analisou-se a extensão da missão institucional das duas instituições que se destacaram nos parâmetros de efetividade estabelecidos pelos estudos que embasam a pesquisa.

Assim, observou-se que há diferenças na extensão das missões. A Unipampa apresenta extensão de 50 palavras, ao passo que a UFMG apresenta extensão de 39 palavras. O que permite concluir que, adotados os elementos propostos por Pearce (1982), a extensão das missões institucionais não possui grande interferência no status quo da declaração, podendo ser desde uma missão curta até uma mais extensa, mas que a efetividade da missão, sob a ótica de Pearce (1982) e Pearce e David (1987) está relacionada ao conteúdo explícito e não na extensão da declaração.

Cumpre ressaltar, no entanto, que embora sejam adotados os estudos de Pearce (1982) e Pearce e David (1987) para as análises, a identificação dos elementos está envolta de certa subjetividade em sua classificação, uma vez que se trata de uma análise de conteúdo e requer inferência própria dos pesquisadores na determinação dos elementos, e caracteriza-se como limitação do presente estudo.

\section{CONCLUSÕES E SUGESTÕES PARA FUTUROS TRABALHOS}

A pesquisa demonstra que se bem elaborada, a declaração de missão pode sim ser considerada uma ferramenta de gestão, auxiliando tanto no planejamento, como na gestão estratégica das instituições.

Os resultados mostram que das 41 Instituições Federais de Ensino Superior (IFES) pesquisadas, 25 estão igual ou abaixo da média, quando se trata de número de elementos efetivos da missão institucional, identificados. Nota-se, todavia, que as instituições dispensam, em sua maioria, especial atenção ao meio externo, focando no compromisso com desenvolvimento sustentável, seja ele através da preocupação econômica, social ou ambiental, e com a referência aos serviços prestados.

Observa-se, entretanto, que as IFES não demonstram grande preocupação em expor uma filosofia e valores próprios em sua declaração de missão, não contemplando no escopo de declaração de missão a visão, valores e princípios da organização, que podem conter tais aspectos.

Observa-se, também, que com a imagem da organização é pouco difundida na missão 
institucional. Outro aspecto relevante, que embora não seja contemplado por Pearce (1982) e David (1987) é a questão da referencia aos stakeholders, especialmente a corpo docente e técnicos administrativos, que juntamente com o corpo discente, são os responsáveis pelo funcionamento da instituição.

Assim, em relação ao objetivo central desse estudo - analisar o status quo da missão institucional das Instituições Federais de Ensino Superior (IFES), com base nos estudos de Pearce (1982) e Pearce e David (1987) - conclui-se que, das IFES pesquisadas, nenhuma apresentou os oito elementos propostos pelos estudos que embasam a pesquisa. A variação de elementos identificados foi de 2 elementos, em cinco instituições, e 7 elementos, em duas instituições, sendo elas a UFMG e a Unipampa, consideradas, portanto, as instituições com missão institucional mais efetivas, dentre as pesquisadas.

Com base na presente pesquisa, conclui-se também que a extensão da missão institucional pode facilitar seu entendimento, mas que o status quo e a efetividade da missão independe da sua extensão, mas sim da clareza com que é construída e da forma com que se contemplam os elementos a serem considerados para que a missão seja efetiva.

A presente pesquisa tenta evidenciar a necessidade de que as missões institucionais sejam bem elaboradas, para que sejam efetivamente válidas e sirvam como suporte a gestão estratégica das instituições, especialmente em se tratando de IFES, para que a missão não seja um mero texto na página da universidade, no seu Plano de Desenvolvimento Institucional, Estatuto ou Regimento Interno.

Assim, a presente pesquisa não pretendeu esgotar as discussões sobre o assunto, mas iniciar uma reflexão sobre. Limitou-se, no entanto, a análise da missão institucional, não incluindo no escopo conceitual destas missões, os itens relativos à visão, valores e princípios da IFES, que não foram considerados para efeitos de análise dos dados. Além disso, ressaltase que a análise dos dados envolveu a subjetividade do pesquisador na classificação dos itens, quando da análise de conteúdo para classificação e identificação dos itens da missão institucional, de acordo com as propostas de Pearce (1982) e Pearce e David (1987).

Desta forma, diante das limitações apresentadas, sugere-se para a continuidade das discussões a respeito da missão institucional das IFES, a inclusão dos elementos de visão, valores e princípios da instituição ao escopo da pesquisa, bem como o aprofundamento das análises, a partir de outros critérios que permitam avaliar a efetividade das missões institucionais. 


\section{REFERÊNCIAS}

AMATO, C. H; AMATO, L. H. Corporate Commitment to Quality of Life: Evidence from Company Mission Statements. Journal of Marketing Theory and Practice, p. 69-87. 2002

ANDIFES. Associação Nacional dos Dirigentes de Instituições Federais de Ensino Superior. Disponível em: <http://www.andifes.org.br/> Acesso em: 22 nov. 2010.

BARDIN, L. Análise de conteúdo. 3. ed. Lisboa: Edições 70, 2004.

BART, C. K. Sex, lies, and mission statement. Business Horizons, nov./dez. 1997.

Exploring the application of mission statements on the World Wide Web. Internet

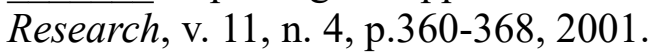

; BAETZ, M. C. The Relationship Between Mission Statements and Firm

Performance: An Exploratory Study. Journal Of Management Studies, Malden, v. 35, n. 6 , p.823-853, nov. 1998.

; BONTIS, N. Distinguishing between the board and management in company mission: Implications for corporate governance. Journal Of Intellectual Capital, v. 4, n. 3, p.361-381, 2003.

; BONTIS, N., TAGGAR, S. A model of mission statements and firm performance. Management Decision, v. 39 n.1, p.19-35, 2001.

; HUPFER, M. Mission statements in Canadian hospitals. Journal Of Health Organisation And Management, v. 18, n. 2, p.92-110, 2004.

BARTKUS, B. R.; GLASSMAN, M. Do Firms Practice What They Preach? The Relationship Between Mission Statements and Stakeholder Management. Journal Of Business Ethics, Amsterdam, v. 83, n. 2, p.207-216, dez. 2008.

; GLASSMAN, M; MCAFEE, B. R. Mission statements: are they smoke and mirrors? Business Horizon. nov./dez. 2000.

BILOSLAVO, R. Web-based mission statements in Slovenian enterprises. Journal for East European Management, v. 9, n.3, p.265-278, 2004

CAMPBELL, A.A mission to succeed. Director, v. 44, n. 7, fev, 1991.

. Mission Statements. Long Range Planning, v. 30, n. 6, p. 931-932, 1997.

COLAUTO, R. D; BEUREN, I M.. Coleta, análise e interpretação dos dados. In: BEUREN, I. M. Como elaborar trabalhos monográficos em contabilidade: teoria e prática. São Paulo: Atlas, 2003. p. 117-144. 
CUNHA, L. A. Brasil. In: ÚNION DE UNIVERSIDADES DE AMÉRICA LATINA. História de las universidades de América Latina. México: UDUAL, 1999. p. 179-254.

DAVID, F. R.; DAVID, F. R. It's time to redraft your mission statement. The Journal of Business Strategy, Boston, v. 24, n. 1, p. 11-4, jan.-fev. 2003.

DRUCKER, P. Administração: responsabilidades, tarefas, práticas. São Paulo: Pioneira, 1975.

FINGER, A. P. Gestão universitária no Brasil: A busca de uma identidade. In: FINGER, A. P. Gestão de universidades: Novas abordagens. Curitiba: Champagnat, 1997.

FUGAZZOTTO, S. J.. Mission Statements, Physical Space, and Strategy in Higher Education. Innovative Higher Education, New York, v. 34, n. 5, p.285-298, dez. 2009.

GIL, A.C. Como elaborar projetos de pesquisa. 4. ed. São Paulo: Atlas, 2007.

GREENGARTEN-JACKSON, J. et al. Mission statements in service and industrial corporations. International Journal Of Quality Science, v. 1, n. 1, p.48-61, abr. 1996.

HARDY, C; FACHIN, R. Gestão estratégica na universidade brasileira: Teoria e casos. Porto Alegre: Editora da Universidade - UFRGS, 1996

INSTITUTO NACIONAL DE ESTUDOS E PESQUISAS EDUCACIONAIS ANÍSIO TEIXEIRA. Evolução do ensino superior: Graduação 1980-1998. Brasília: MEC, 2000.

LEUTHESSER, L.; KOHLI C. Corporate Identity: The Role of Mission Statements. Business Horizons, Greenwich, v. 40, n. 3, p. 59-66, maio-jun. 1997.

LINO, M. R. O. Métodos estatísticos I. Florianópolis: Departamento de Ciências Contábeis/UFSC, 2008

MEC. Ministério da Educação. Disponível em: $<$ http://portal.mec.gov.br/index.php $>$. Acesso em: 27 nov. 2010.

NIMWEGEN, G. V. et al. A stakeholder perspective on mission statements: an international empirical study. International Journal of Organizational Analysis, Amsterdam, v. 16, n. 1/2, p.61-82, 2008.

OMRAN, M., ATRILL, P., POINTON J. Shareholders versus stakeholders: Corporate mission statements and investor returns. Business Ethics: A European Review, v. 11, n. 34, p. 318-327, 2002.

PEARCE, J. A. II. The company mission as a strategic tool. Sloan Management, v. 23, n.3, p.15, 1982.

; DAVID, F. Corporate mission statement: the botton line. The Academy of management Executive, n. 2, v.1, p. 109-116, Mai. 1987. 
RARICK, C. A; VITTON, J. Mission statement make cents. The journal of business strategy, v. 16, n. 1, p.11, jan./fev. 1995.

RIBEIRO, A. M. et al. Missão Institucional: Uma análise do status quo e dos principais elementos presentes nas missões de empresas brasileiras de capital aberto. In: ENCONTRO ANUAL DA ANPAD, 32, 2008, Rio de Janeiro. Anais... Rio de Janeiro: ANPAD, 2008. CD ROM.

RICHARDSON, R. J. Pesquisa social: métodos e técnicas. 2. ed. São Paulo: Atlas, 1989.

SMITH, M. et al. Do mission statements accomplish their missions? An exploratory analysis of mission statement content and organizational longevity. Journal of Applied Management and Entrepreneurship, v. 25, n. 6, p.75-96, 2001

SUFY; LYON .S H: Mission statements exposed. International Journal of Contemporary Hospitality Management, v. 15, p. 255-262, 2003.

TAKESKI, T., REZENDE, W., Estratégia Empresarial: Tendências e Desafios - um enfoque na realidade brasileira. São Paulo: Makron Books, 2000.

TELES, J; LUNKES, R.J. Efetividade da missão institucional: Um estudo nas 100 maiores empresas de capital aberto no Brasil. In: CONGRESSO ANPCONT, 5, 2008, Vitória. Anais... São Paulo: ANPCont, 2011.

TRIPODI, T; FELLIN, P; MEYER, H. J. Análise da pesquisa social: Diretrizes para o uso de pesquisa em serviço social e ciências sociais. 2. Ed. Rio de Janeiro: Francisco Alves, 1981.

VALADARES, M.C.B. Planejamento Estratégico Empresarial. QualityMark, Rio de Janeiro, 2002. 